\title{
Indium-Doped Zinc Oxide Thin Films as Effective Anodes of Organic Photovoltaic Devices
}

\author{
Ziyang Hu, Baochen Jiao, Jianjun Zhang, Xiaodan Zhang, and Ying Zhao \\ Key Laboratory of Photo-Electronics Thin Film Devices and Technique of Tianjin, Institute of Photo-Electronic Thin Film Device and \\ Technique of Nankai University, Key Laboratory of Opto-Electronic Information Science and Technology for Ministry of Education, \\ Tianjin 300071, China
}

Correspondence should be addressed to Jianjun Zhang, jjzhang@nankai.edu.cn

Received 29 June 2011; Revised 31 August 2011; Accepted 5 September 2011

Academic Editor: Gaetano Di Marco

Copyright ( $) 2011$ Ziyang Hu et al. This is an open access article distributed under the Creative Commons Attribution License, which permits unrestricted use, distribution, and reproduction in any medium, provided the original work is properly cited.

\begin{abstract}
Indium-doped zinc oxide (IZO) thin films were prepared by low-cost ultrasonic spray pyrolysis (USP). Both a low resistivity $\left(3.13 \times 10^{-3} \Omega \mathrm{cm}\right)$ and an average direct transmittance $(400 \sim 1500 \mathrm{~nm})$ about $80 \%$ of the IZO films were achieved. The IZO films were investigated as anodes in bulk-heterojunction organic photovoltaic (OPV) devices based on poly(3-hexylthiophene) and $[6,6]$-phenyl $\mathrm{C}_{61}$-butyric acid methyl ester. The device fabricated on IZO film-coated glass substrate showed an open circuit voltage of $0.56 \mathrm{~V}$, a short circuit current of $8.49 \mathrm{~mA} \mathrm{~cm}^{-2}$, a fill factor of 0.40 , and a power conversion efficiency of $1.91 \%$, demonstrating that the IZO films prepared by USP technique are promising low In content and transparent electrode candidates of low-cost OPV devices.
\end{abstract}

\section{Introduction}

Organic photovoltaics (OPVs) have attracted considerable attentions for use as the next generation of renewable energy sources, due to their simple cell structure, ease of fabrication, low cost, and flexibility [1-3]. To fabricate costefficient and large area OPVs, it is imperative to develop low-cost transparent conducting oxide (TCO) electrodes, which can substitute for the conventional indium tin oxide (ITO) electrodes and a highly efficient TCO deposition process. Considering the cost advantage of OPVs, ITO film is not a desirable anode material, due to the high cost and shortage of indium [4]. Therefore, extensive efforts are being dedicated to finding low/non-In TCOs which are inexpensive but have higher conductivity and a broader transparency window than ITO [5-12]. In addition, the conventional sputtering process is not acceptable in low-cost OPVs due to its low target usage, clumsy equipments, and necessity of vacuum-based condition. Recently, ultrasonic spray pyrolysis (USP) has received extra-attentions because of its simplicity, suitability for product industrialization, and atmosphericpressure solution deposition routes [13-16]. Wienke et al. have used USP to fabricate IZO thin film, which were used in amorphous silicon solar cells as transparent anodes. However, there have been few studies on investigation of the fabrication of OPVs on the UPS-deposited IZO electrodes, which would be beneficial for the low-cost production of OPVs [17].

In this work, we report the electrical and optical properties of low indium IZO electrodes prepared by USP technique. An efficient OPV device fabricated on the IZOcoated glass was achieved. The performance of OPV device fabricated on both commercial ITO and USP-deposited IZO are compared.

\section{Experimental Details}

IZO thin films were prepared on glass substrates (Corning eagle 2000) by USP. A $0.2 \mathrm{~mol} / \mathrm{L}$ solution of zinc acetate dehydrate $\left[\mathrm{Zn}\left(\mathrm{CH}_{3} \mathrm{COO}\right)_{2} \cdot 2 \mathrm{H}_{2} \mathrm{O}\right]$ diluted in ethanol, and deionized water $(3: 1)$ was used for the film, and indium acetate $\left[\operatorname{In}\left(\mathrm{CH}_{3} \mathrm{COO}\right)_{3}\right]$ was added to initial solution for indium doping. The In/Zn ratio was 1.5 at \%. The glacial acetic acid was added into the precursor solution at $18 \mathrm{vol}$. $\%$ content. After the glass substrate was heated to $480^{\circ} \mathrm{C}$, the aerosol of initial solution was nebulized by an ultrasonic 


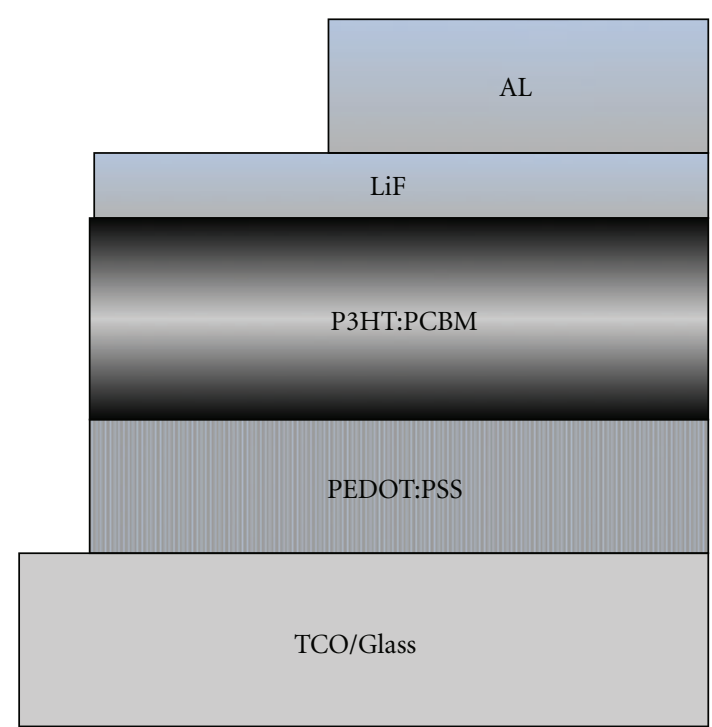

(a)

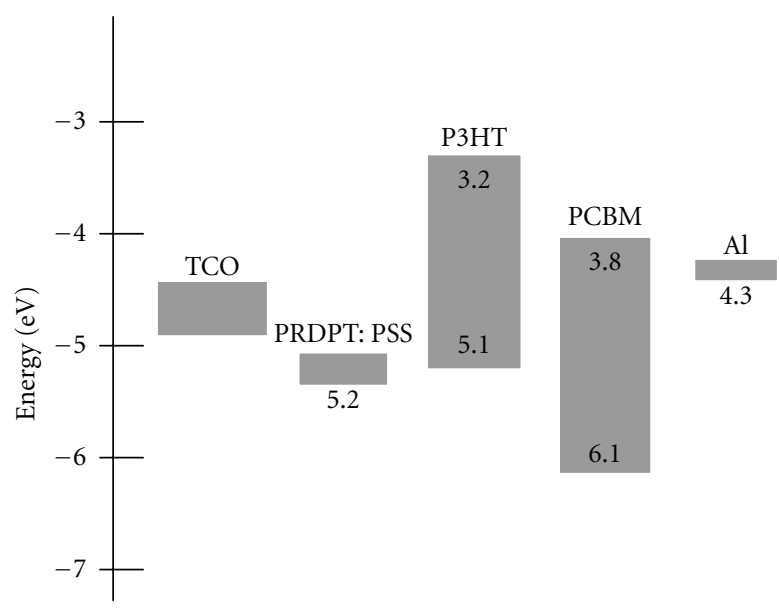

(b)

Figure 1: (a) Device structure and (b) energy diagram of OPVs.

agitation with $1.7 \mathrm{MHz}$ and transported into the growth chamber by air at a flow rate of $11 \mathrm{~L} / \mathrm{min}$. The $\mathrm{IZO}$ film with $\sim 600 \mathrm{~nm}$ thicknesses was measured by step profilometer (AMBIOS-XP2) and field emission scanning electron microscope (FE-SEM, JSM-6700F). The electrical properties were obtained by Hall-effect measurements using Van der Pauw method (Accent HL5500 PC). The surface morphology was observed by SEM. The direct transmittances of thin films were evaluated by UV-visible-NIR spectrometer (Cary 5000 UV-VIS produced by Varian Company). The root mean square roughness (RMS) was taken in a contact mode with an atomic force microscope (AFM, SPA-400 SPM UNIT product by Seiko Instruments Inc.).

Conventional OPVs were fabricated on the USP-grown IZO electrode to investigate the effect of the sheet resistance, transmittance and work function of the USP-grown IZO electrode on the performance of the OPVs. To fabricate the OPVs, IZO electrodes were cleaned with detergent, ultrasonicated in acetone and isopropyl alcohol, and subsequently dried in an oven overnight. Conducting PEDOT:PSS (Baytron P VP AI 4083) was spin-cast (5000 rmp) with thickness about $40 \mathrm{~nm}$ from aqueous solution (after passing a $0.45 \mu \mathrm{m}$ filter). A blend solution of $15 \mathrm{mg}$ of poly(3hexylthiophere) (P3HT) and $12 \mathrm{mg}$ of $[6,6]$-phenyl $\mathrm{C}_{61}$ butyric acid methyl ester (PCBM) in $1 \mathrm{~mL}$ of chlorobenzene was spin-coated on top of the respective PEDOT:PSS layers. Subsequently, the devices were pumped down in vacuum $\left(10^{-4} \mathrm{~Pa}\right)$, and an $\mathrm{LiF}(1 \mathrm{~nm}) / \mathrm{Al}(100 \mathrm{~nm})$ film used as the cathode was deposited on top of the active layer. The reference devices were fabricated on commercial ITO glass substrates in the same manner. OPVs with a structure of TCO/PEDOT:PSS/P3HT:PCBM/LiF/Al were completed. The schematic diagram is shown in Figure 1(a). The active area of the devices was $0.08 \mathrm{~cm}^{2}$ defined by the shade mask. Device current density-voltage $(J-V)$ characteristics were measured

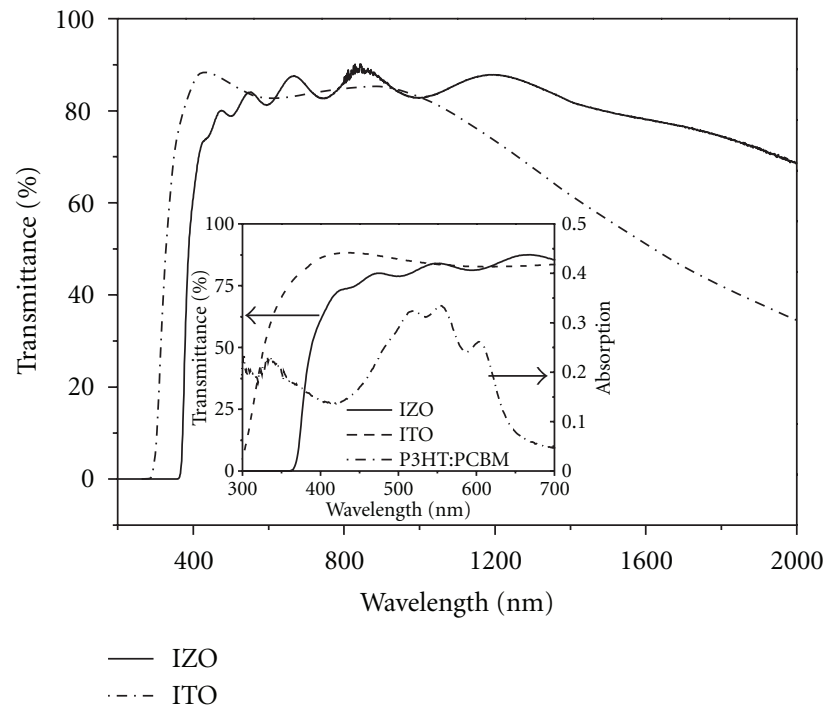

Figure 2: Transmittance of IZO- and ITO-coated glass substrates from ultraviolet to near-infrared region. Inset indicates transmittance of IZO- and ITO-coated glass substrates with respect to the absorbance of the P3HT:PCBM films.

using a Keithley 2420 under $100 \mathrm{~mW} / \mathrm{cm}^{2}$ simulated AM $1.5 \mathrm{G}$ solar illumination calibrated using a Si photodetector. All of the measurements were fabricated and tested in ambient conditions in air.

\section{Results and Discussions}

As shown in Figure 2, the transparency of IZO-coated glass extents well into the near infrared region (NIR) and exhibits transmittance $>80 \%$ around $1500 \mathrm{~nm}$. The high transparency of IZO film in the NIR suggests the potential 


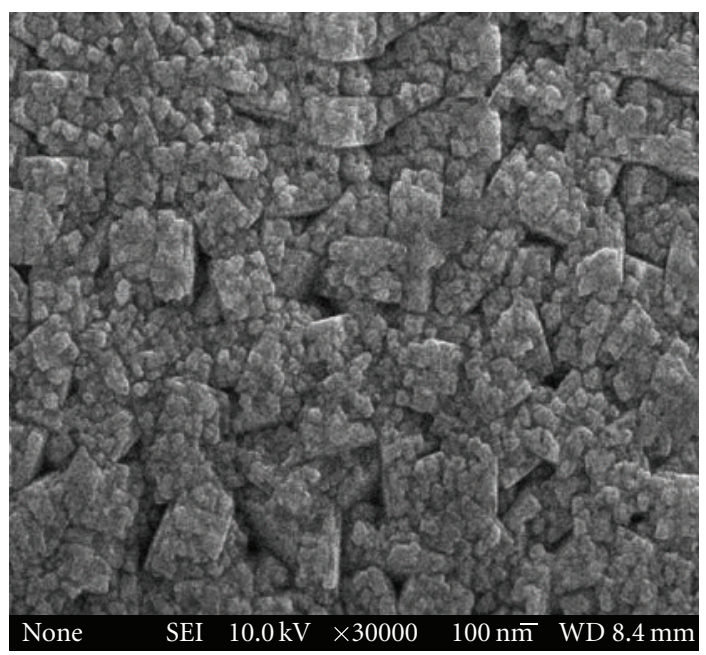

(a)

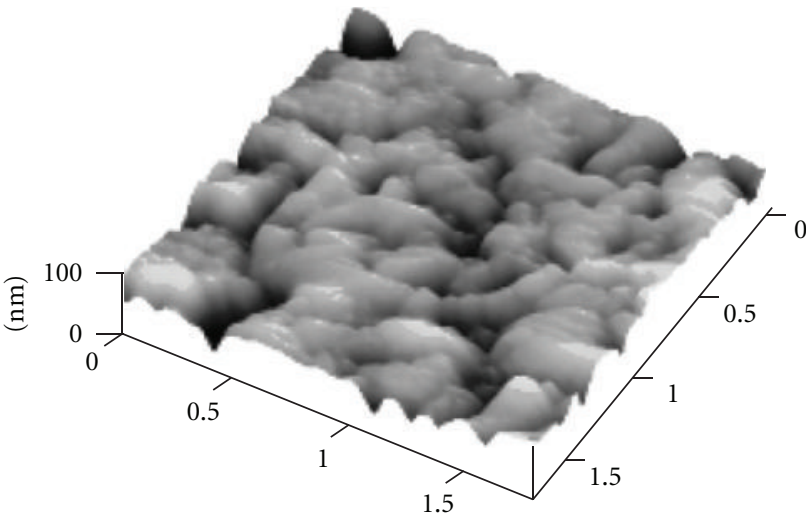

$(\mu \mathrm{m})$

(b)

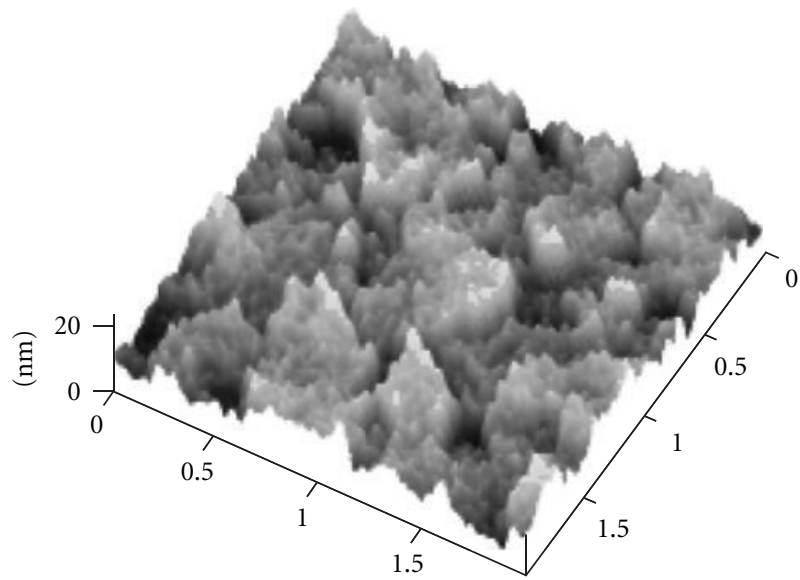

$(\mu \mathrm{m})$

(c)

FIGURE 3: (a) Scanning electron microscope (SEM) image of IZO film prepared by ultrasonic spray pyrolysis. The topography of (b) IZO-coated glass and (c) ITO-coated glass substrates measured using atomic force microscopy (AFM). The root mean square surface roughness is $12.37 \mathrm{~nm}$ for IZO and $2.41 \mathrm{~nm}$ for ITO. application in stacked cell where high NIR transmittance is required. In contrast, the transmittance of commercial ITOcoated glass decreases in the NIR $(<1000 \mathrm{~nm})$ due to the high degree of free-carrier absorption [18]. From Figure 2, it is perceptible that the transmission window of the IZOcoated glass is significantly larger than that of the ITOcoated glass. The high transparency is ascribed to the lower carrier density $\left(1.54 \times 10^{20} \mathrm{~cm}^{-3}\right)$ according to the Drude model [19]. The measured resistance of IZO-coated glass is $3.14 \times 10^{-3} \Omega \mathrm{cm}$, higher than that of commercial ITOcoated glass $\left(4.58 \times 10^{-4} \Omega \mathrm{cm}\right)$. These optical and electrical characteristics of the IZO films make this material suitable for solar cell applications.

A comparison of the surface roughness between the IZOand ITO-coated glass substrates is shown in Figures 3(b) and 3(c), respectively. The AFM images reveal that the IZO film forms large irregular crystals, resulting in a surface root mean square (RMS) roughness of $12.37 \mathrm{~nm}$ as shown in Figure 3(b). In contrast, the ITO film forms small crystal grains and has a comparatively smooth surface with a RMS roughness of $2.41 \mathrm{~nm}$ as shown in Figure 3(c). Although the rough surface of the IZO may induce direct contact between the oxide anode and the $\mathrm{Al}$ cathode, spin-coating a $\sim 40 \mathrm{~nm}$ thick PEDOT:PSS buffer layer on the IZO film surface prior to spin-coating of the active layer smooths the rough surface and eliminates these shorts.

Device A with the structure of IZO/PEDOT: PSS/P3HT: $\mathrm{PCBM} / \mathrm{LiF} / \mathrm{Al}$ and Device $\mathrm{B}$ with the structure of ITO/ PEDOT:PSS/P3HT:PCBM/LiF/Al were fabricated, respectively. The $J-V$ curves in the dark and under simulated AM 1.5 conditions $\left(100 \mathrm{~mW} / \mathrm{cm}^{2}\right)$ of the devices $\mathrm{A}$ and $\mathrm{B}$ are shown in Figure 4. Under illumination, the device A yields a $V_{\mathrm{oc}}$ of $0.56 \mathrm{~V}$, a $J_{\mathrm{sc}}$ of $8.49 \mathrm{~mA} / \mathrm{cm}^{2}$, an FF of 0.40 , and a power conversion efficiency (PCE) of $1.91 \%$, which is inferior to the performance of the device B with an efficiency of $3.24 \%$. The slopes at the short circuit point and at the open circuit voltage are the inverse values of the shunt resistance $\left(R_{\mathrm{sh}}\right)$ and the series resistance $\left(R_{\mathrm{s}}\right)$ of the equivalent circuit scheme of a solar cell, respectively. The estimated values of $R_{\mathrm{s}}$ and $R_{\mathrm{sh}}$ are presented in Table 1.

The measured short circuit currents of the devices A and $B$ were nearly identical, from which we may conclude that there was little change in the optical field distribution, or in charge collection efficiency. From the inset of Figure 2, it can be seen that the absorption domain of the blend of P3HT:PCBM, the photoconductive films of the organic cells, is mainly situated in the region of large transparency of IZO-coated glass. The average of transmittance of IZO is appreciably less than that of ITO in the range of $350 \sim 650 \mathrm{~nm}$, which may result in the lower current density than that of device $\mathrm{B}$.

The device made with IZO exhibited similar $V_{\text {oc }}$ than did those made with ITO. The value of $V_{\mathrm{oc}}$ is also similar to the previous results. If both electrodes establish ohmic contacts with the active layer, $V_{\mathrm{oc}}$ in these bulk-heterojunction cells is related directly to the energy difference between the HOMO level of the donor (P3HT) and the LUMO level of the acceptor (PCBM) components. As shown in Figure 1(b), 


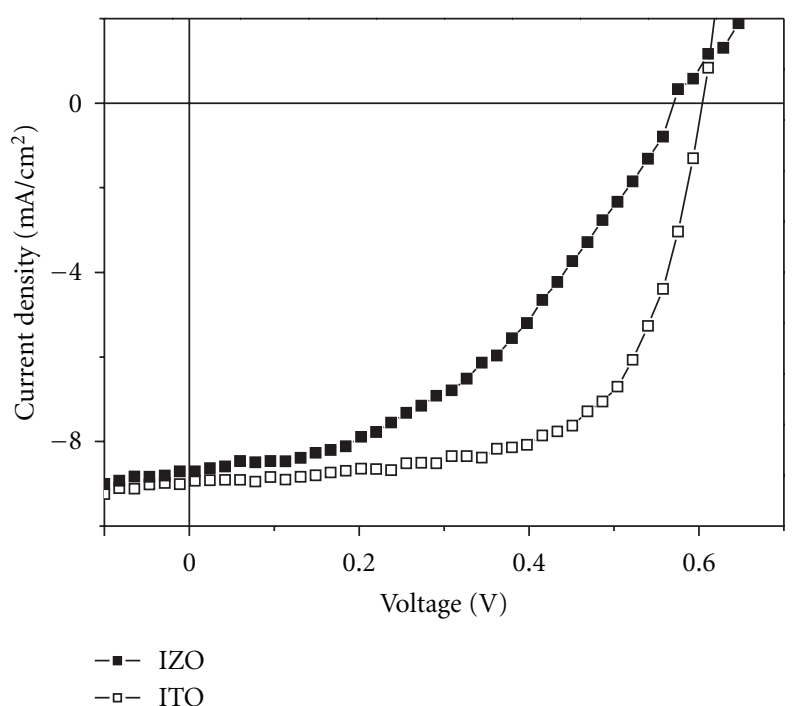

(a)

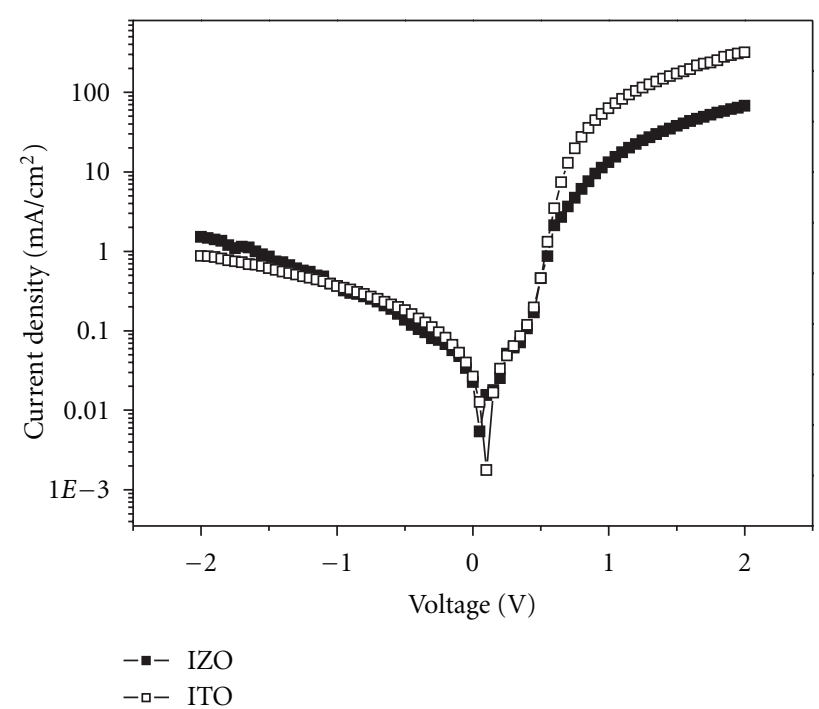

(b)

Figure 4: Current density-voltage $(J-V)$ characteristics of FTO/PEDOT:PSS/P3HT:PCBM/LiF/Al and ITO/PEDOT:PSS/P3HT:PCBM/LiF/Al photovoltaic devices (a) under simulated AM 1.5 conditions and (b) in the dark.

TABLE 1: Detailed performance parameters of the OPVs fabricated on the IZO- and ITO-coated glass substrates.

\begin{tabular}{lccccccc}
\hline Device & Anode & $J_{\mathrm{sc}}\left(\mathrm{Ma} \mathrm{cm}^{-2}\right)$ & $V_{\mathrm{oc}}(\mathrm{V})$ & $\mathrm{FF}(\%)$ & PCE $(\%)$ & $R_{\mathrm{s}}\left(\Omega \mathrm{cm}^{2}\right)$ & $R_{\mathrm{sh}}\left(\Omega \mathrm{cm}^{2}\right)$ \\
\hline A & IZO & 8.49 & 0.56 & 40 & 1.91 & 32.25 & 284.45 \\
B & ITO & 8.95 & 0.59 & 61 & 3.24 & 8.08 & 584.79 \\
\hline
\end{tabular}

the introduction of high work function of PEDOT:PSS as a buffer layer, ohmic contacts between TCO and active layer are achieved, resulting in better hole extraction. Therefore, PEDOT:PSS buffer layer not only planarizes the IZO surface, but also induces the ohmic contact between TCO and active layer. Slight variation in $V_{\mathrm{oc}}$ values may arise from pinholes, which short-circuits the photovoltaic cell resulting in large leak current. For a conventional $p-n$ junction solar cell the $V_{\text {oc }}$ is given by the formula

$$
V_{\mathrm{oc}}=\left(\frac{n k T}{q}\right) \ln \left(\frac{J_{\mathrm{sc}}}{J_{\mathrm{s}}}+1\right),
$$

where $J_{s}$ is the saturation current density, $q$ is the elementary charge, $k$ is Boltzmann's constant, $T$ is temperature, and $n$ is the ideality factor, $J_{\mathrm{sc}}$ is the short circuit current density. The values of $V_{\text {oc }}$ derived from experimental light $J$ - $V$ curves of devices $\mathrm{A}$ and $\mathrm{B}$ fit to the above equation agree with the measured values well.

In Figure 4(b), the dark $J-V$ characteristics of the devices $A$ and $B$ are shown on a logarithmic scale. The devices A and $B$ almost present the same reverse biased current, which suggest the smooth effect of PEDOT:PSS on relatively rough IZO-coated glass. The influence of the buffer layer can be observed in the $J-V$ curves under lower bias in the dark. The $J-V$ curves were first symmetric, and then reached the injection limit at forward bias. At further increase of forward bias the current approached a space charge limited condition and the difference among the $J-V$ curves of the diodes with different buffer layers is small. This is because the current in this region mainly depends on the mobility of charge carriers in the active layers. Under forward bias, the difference of ohmic contributions and injection limit in diodes reflect the hole injection from anode to active layer via the buffer layer, because the electron injection conditions are the same in the devices $\mathrm{A}$ and $\mathrm{B}$. This indicates that the injection capabilities of these buffer layers are the same as well. At high forward bias, the current density of device B is obviously larger than that of device $\mathrm{A}$, which is ascribed to the lower resistance of ITO films, indicating superior FF of device B [2]. To overcome FF losses in solar cells, future research should concentrate on increasing the layer conductivity and enhancing the surface smoothness of the films without losing the transmittance.

\section{Conclusion}

In summary, this study investigates atmospheric-pressure solution deposition routes as an alternative to these traditional high-vacuum techniques. Solution processing is attractive due to its ease and potential to lower devicemanufacturing costs. We demonstrated that USP-grown IZO electrodes are promising low-cost anode materials. Due to the relatively low resistivity and high transmittance extended to NIR, which is a critical benefit for the fabrication of lowcost OPVs. More importantly, considering the materials cost and process efficiency, it is believed that low In IZO electrodes grown by the USP method are better suited to costefficient OPVs than the batch-type grown ITO electrodes. 
Furthermore, it was found that the performance of the OPV fabricated on the UPS-grown IZO electrodes depends mainly on the sheet resistance and surface morphology of the IZO electrodes, regardless of the work function, due to the existence of a PEDOT:PSS ohmic layer connecting the anode and the active layer. The presented results demonstrate that USP is a promising method for the deposition of IZO thin films and can be used as replacement for the ITO electrode. In addition, the IZO film with high transparency in the NIR appears very promising in stacked solar cells with absorption of full wavelength spectrum. This may lead to higher efficiency organic multijunction photovoltaic cells.

\section{Acknowledgments}

This work was supported by the National Basic Research Program of China (Grants no. 2011CBA00705, 2011CBA00706, and 2011CBA00707), and the National High-tech R\&D Program (Grant no. 2009AA050602).

\section{References}

[1] W. Ma, C. Yang, X. Gong, K. Lee, and A. J. Heeger, "Thermally stable, efficient polymer solar cells with nanoscale control of the interpenetrating network morphology," Advanced Functional Materials, vol. 15, no. 10, pp. 1617-1622, 2005.

[2] J. Xue, S. Uchida, B. P. Rand, and S. R. Forrest, "Asymmetric tandem organic photovoltaic cells with hybrid planar-mixed molecular heterojunctions," Applied Physics Letters, vol. 85, no. 23, pp. 5757-5759, 2004.

[3] G. Chidichimo and L. Filippelli, "Organic solar cells: problems and perspectives," International Journal of Photoenergy, vol. 2010, Article ID 123534, 11 pages, 2010.

[4] T. Minami, "Transparent conducting oxide semiconductors for transparent electrodes," Semiconductor Science and Technology, vol. 20, no. 4, pp. S35-S44, 2005.

[5] E. J. J. Martin, M. Yan, M. Lane, J. Ireland, C. R. Kannewurf, and R. P. H. Chang, "Properties of multilayer transparent conducting oxide films," Thin Solid Films, vol. 461, no. 2, pp. 309-315, 2004.

[6] J. Ni, H. Yan, A. Wang et al., "Synthesis and characterization of volatile zinc MOCVD precursors and their implementation in growth of highly transparent, conducting zinc- and tin-doped indium oxide anodes for polymer light-emitting diodes," Journal of the American Chemical Society, vol. 127, no. 15, pp. 5613-5624, 2005.

[7] Y. Yang, L. Wang, H. Yan, S. Jin, T. J. Marks, and S. Li, "Highly transparent and conductive double-layer oxide thin films as anodes for organic light-emitting diodes," Applied Physics Letters, vol. 89, no. 5, pp. 051116-051118, 2006.

[8] Z. Hu, J. Zhang, Z. Hao, Q. Hao, X. Geng, and Y. Zhao, "Highly efficient organic photovoltaic devices using F-doped $\mathrm{SnO}_{2}$ anodes," Applied Physics Letters, vol. 98, no. 12, pp. 123302123304, 2011.

[9] J. A. Jeong, H. K. Kim, and S. I. Na, "Low resistance and high transparent amorphous IZTO electrode cosputtered by linear facing target sputtering for organic photovoltaics," Electrochemical and Solid-State Letters, vol. 12, no. 9, pp. J80J82, 2009.

[10] V. Bhosle, J. T. Prater, F. Yang, D. Burk, S. R. Forrest, and J. Narayan, "Gallium-doped zinc oxide films as transparent electrodes for organic solar cell applications," Journal of Applied Physics, vol. 102, no. 2, pp. 023501-023505, 2007.

[11] G. B. Murdoch, S. Hinds, E. H. Sargent, S. W. Tsang, L. Mordoukhovski, and Z. H. Lu, "Aluminum doped zinc oxide for organic photovoltaics," Applied Physics Letters, vol. 94, no. 21, pp. 213301-213303, 2009.

[12] F. Yang and S. R. Forrest, "Organic solar cells using transparent $\mathrm{SnO}_{2}-\mathrm{F}$ anodes," Advanced Materials, vol. 18, no. 15, pp. 20182022, 2006.

[13] M. D. L. L. Olvera, H. Gómez, and A. Maldonado, "Doping, vacuum annealing, and thickness effect on the physical properties of zinc oxide films deposited by spray pyrolysis," Solar Energy Materials and Solar Cells, vol. 91, no. 15-16, pp. 1449-1453, 2007.

[14] J. Wienke and A. S. Booij, "ZnO: in deposition by spray pyrolysis-influence of the growth conditions on the electrical and optical properties," Thin Solid Films, vol. 516, no. 14, pp. 4508-4512, 2008.

[15] J. M. Bian, X. M. Li, X. D. Gao, W. D. Yu, and L. D. Chen, "Deposition and electrical properties of N-In codoped ptype $\mathrm{ZnO}$ films by ultrasonic spray pyrolysis," Applied Physics Letters, vol. 84, no. 4, pp. 541-543, 2004.

[16] H. Gomez, A. Maldonado, M. D. L. L. Olvera, and D. R. Acosta, "Gallium-doped $\mathrm{ZnO}$ thin films deposited by chemical spray," Solar Energy Materials and Solar Cells, vol. 87, no. 1-4, pp. 107-116, 2005.

[17] J. Wienke, B. van der Zanden, M. Tijssen, and M. Zeman, "Performance of spray-deposited $\mathrm{ZnO}$ : in layers as front electrodes in thin-film silicon solar cells," Solar Energy Materials and Solar Cells, vol. 92, no. 8, pp. 884-890, 2008.

[18] M. Yang, J. Feng, G. Li, and Q. Zhang, “Tungsten-doped $\operatorname{In}_{2} \mathrm{O}_{3}$ transparent conductive films with high transmittance in nearinfrared region," Journal of Crystal Growth, vol. 310, no. 15, pp. 3474-3477, 2008.

[19] T. J. Coutts, D. L. Young, and X. Li, "Characterization of transparent conducting oxides," MRS Bulletin, vol. 25, no. 8, pp. 58-65, 2000. 


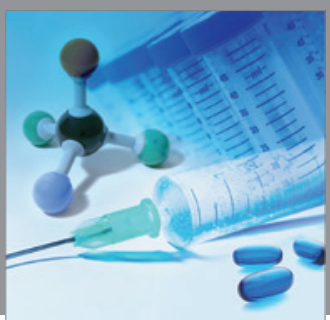

International Journal of

Medicinal Chemistry

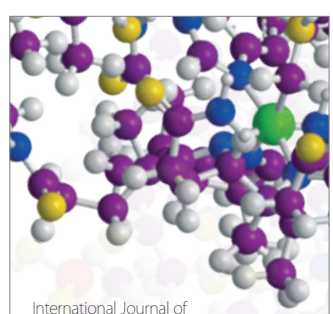

Carbohydrate Chemistry

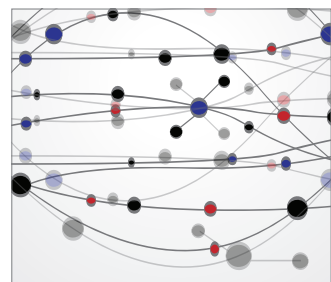

The Scientific World Journal
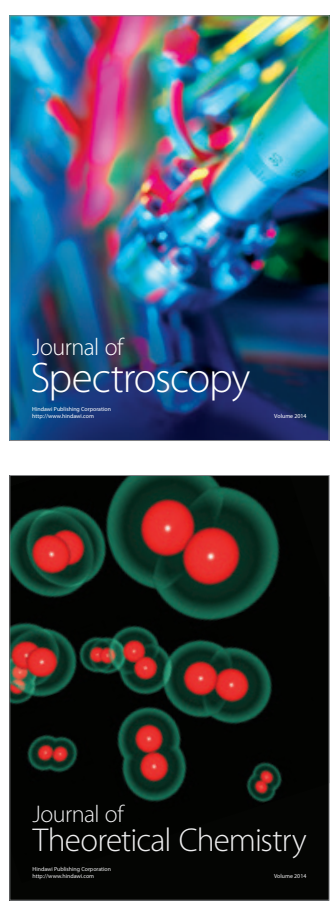
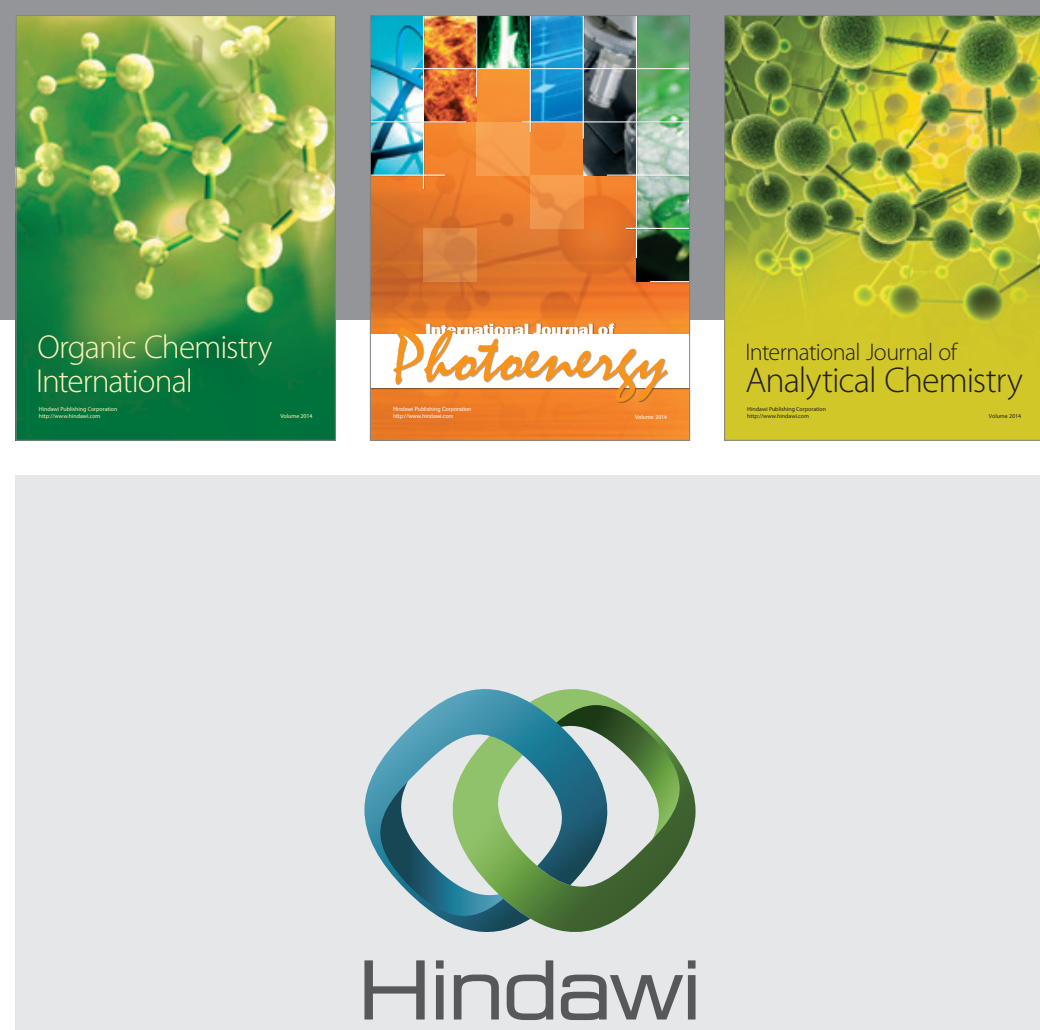

Submit your manuscripts at

http://www.hindawi.com
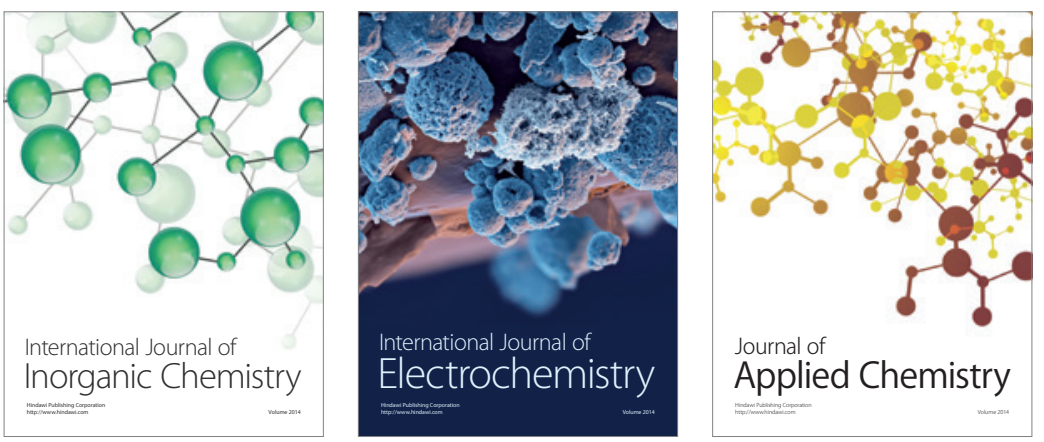

Journal of

Applied Chemistry
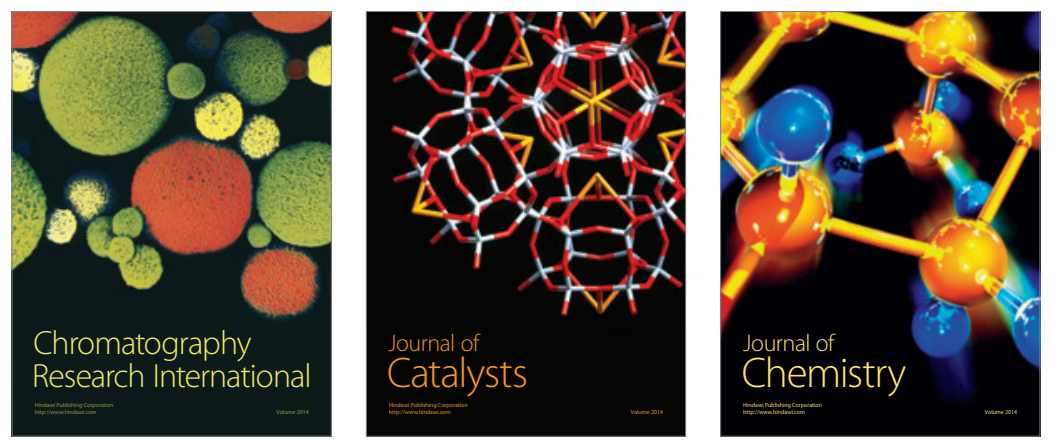
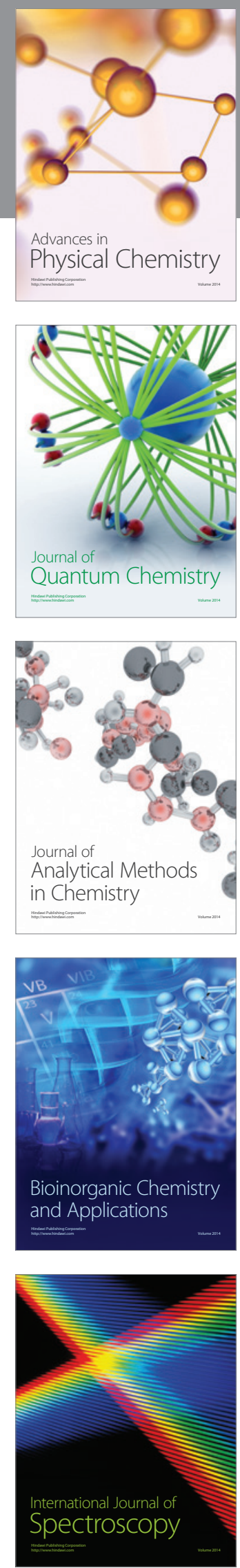